\title{
PENERAPAN PERHITUNGAN PENYUSUTAN AKTIVA TETAP PADA UD. DND MENGGUNKAN METODE GARIS LURUS
}

Ni Made Dwi Ardani Suyasa ${ }^{1}$

Universitas Terbuka, Tangerang

dwi.ardani.suyasa@gmail.com

\begin{abstract}
Abstrak
Tujuan Penelitian Adalah Untuk Melihat Apakah Penerapan Perhitungan Penyusutan Aktiva Tetap Pada Ud. Dnd Menggunkan Metode Garis Lurus Sudah Tepat. Jenis penelitian yang digunakan ialah penelitian deskriptif dengan menggunakan pendekatan kuantitatif. Hasil penelitian adalah Menggunakn metode garis lurus lebih mudah di gunakan dan di pahami dari segi perhitungannya dengan menggunakan rumus di atas. Dan pencatatan aktiva tetap bisa di lakukan dengan benar karena sudah menghitung penyusutan pertahunnya tetap sama.
\end{abstract}

Kata-kata Kunci: Aktiva Tetap. Deskriptif. Garis Lurus

Abstract

The research objective is to see whether the application of depreciation of fixed assets in Ud. Dnd Using the Straight-Line Method Is Right. This type of research is a descriptive study using a quantitative approach. The result of the research is that using the straight-line method is easier to use and understand in terms of its calculation using the formula above. And recording of fixed assets can be done correctly because the annual depreciation has remained the same.

Keyword: Fixed assets. Descriptive. Straight line

\section{PENDAHULUAN}

Aktiva perusahaan merupakan harta yang dimiliki perusahaan dan dapat digunakan untuk operasional perusahaan (Rachmawati, 2018). Dengan meningkatnya nilai total aktiva, maka kepercayaan kreditur akan bertambah karena membaiknya rasio keuangan terutama debt to total asset dan debt to equity (Wijaya \& Supandi, 2017). Aktiva ini berfungsi untuk mendukung menjalankan kegiatannya, yaitu kegiatan yang dilakukan perusahaan dalam rangka memperoleh dana. Aktiva tetap memiliki peranan penting dalam menyediakan informasi yang bermanfaat bagi kreditor dan investor (Bramasto, 2007).

Aktiva terbagi menjadi dua yaitu aktiva lancar dan aktiva tetapAktiva tetap adalah salah satu bagian utama dari kekayaan perusahaan yang berjumlah besar dan mengalami penyusutan dalam satu periode akuntansi (accounting period). Aktiva tetap dapat diperoleh dengan beberapa cara seperti membeli secara tunai, secara kredit atau angsuran, pertukaran, penerbitan surat berharga, dibangun sendiri, sewa guna usaha atau leasing dan donasi (Budiman et al., 2014).

Penyusutan aktiva tetapnya dengan menggunakan metode Garis Lurus sangat baik digunakan karena, implikasinya terhadap laba lebih tinggi nilainya dibandingkan dengan menggunakan metode perhitungan Saldo Menurun Ganda dan metode Jumlah Angka Tahun (Mairuhu \& Tinangon, 2014). Pengukuran aktiva tetap terjadi ketika pengakuan awal dan setelah aktiva tetap telah diakui.Pengukuran aktiva pada saat pengakuan awal dilakukan dengan mengukur semua biaya perolehan.Dan ketika aktiva telah diakui perusahaan, 
mengukur aktiva menggunakan dua metode yaitu metode biaya dan metode revaluasi (Pontoh et al., 2016).

Aktiva tetap adalah aktiva berwujud yang dimiliki untuk digunakan dalam produksi atau penyediaan barang dan jasa untuk direntalkan kepada pihak lain, atau untuk tujuan administratif; dan diharapkan untuk digunakan selama lebih dari satu periode (Koapaha et al., 2014). Beberapa alternatif pembiayaan pembelian aktiva tetap adalah pembiayaan secara tunai, kredit atau secara leasing. Pembiayaan tunai merupakan salah satu jenis pembiayaan dengan memanfaatkan kas atau uang tunai yang dapat dipakai oleh suatu perusahaan (Poere \& Rosita, 2013).

Tujuan Penelitian Adalah Untuk Melihat Apakah Penerapan Perhitungan Penyusutan Aktiva Tetap Pada Ud. Dnd Menggunkan Metode Garis Lurus Sudah Tepat?

\section{METODE}

Jenis penelitian yang digunakan ialah penelitian deskriptif dengan menggunakan pendekatan kuantitatif (Dokman Marulitua Situmorang, 2019). Dalam penelitian ini menggunakan analisis data deskriptif. Dengan metode analisis ini peneliti akan mengumpulkan, menyusun, mengolah dan menganalisis data, agar dapat memberikan gambaran mengenai suatu keadaan tertentu maka dapat ditarik kesimpulan sehingga dapat diketahui apakah perusahaan sudah melakukan perencanaan pajak melalui metode penyusutan akiva tetap (Ratag, 2013). Teknik ini dalam menentukan sampel perlu mempertimbangkan beberapa hal yang dijadikan sebagai kriteria pengambilan sampel (Dokman Marulitua Situmorang, Erlina, 2018).

\section{HASIL DAN PEMBAHASAN}

\section{Tabel.1}

Aktiva Tetap

\begin{tabular}{|c|l|c|c|r|}
\hline No & \multicolumn{1}{|c|}{ Aktiva Tetap } & $\begin{array}{c}\text { Harga Perolehan } \\
(\mathbf{R p})\end{array}$ & $\begin{array}{c}\text { Umur Ekonomis } \\
(\mathbf{T h})\end{array}$ & $\begin{array}{c}\text { Nilai Residu } \\
(\mathbf{R p})\end{array}$ \\
\hline 1 & Mesin Foto Copy & $28.000 .000,-$ & 10 Tahun & $2.000 .000,-$ \\
\hline 2 & Mesin Laminating & $1.600 .000,-$ & 5 Tahun & $200.000,-$ \\
\hline 3 & $\begin{array}{l}\text { Mesin Potong } \\
\text { Kertas }\end{array}$ & $2.500 .000,-$ & 5 Tahun & $400.000,-$ \\
\hline 4 & Laptop & $3.800 .000,-$ & 5 Tahun & $500.000,-$ \\
\hline 5 & Printer & $700.000,-$ & 5 Tahun & $0,-$ \\
\hline
\end{tabular}

Tabel. 1 ini berisikan data Aktiva Tetap UD. DND yang akan di susutkan menggunkan metode garis lurus table 1.1 ini berisikan data nama Aktiva Tetap, harga perolehan aktiva Tetap, umur ekonomis aktiva tetap, dan perkiraan nilai residu aktiva tetap tersebut.

\section{Tabel.2}

Penyusutan Aktiva Tetap Mesin Foto Copy Dengan Metode Garis Lurus

\begin{tabular}{|c|c|c|c|c|}
\hline Tahun & $\begin{array}{c}\text { Harga } \\
\text { Perolehan } \\
\text { (Rp) }\end{array}$ & $\begin{array}{c}\text { Depresiasi per } \\
\text { Tahun } \\
\text { (Rp) }\end{array}$ & $\begin{array}{c}\text { Akum. Depresiasi } \\
\text { Akhir Tahun } \\
\text { (Rp) }\end{array}$ & $\begin{array}{c}\text { Nilai Buku } \\
\text { Akhir Tahun } \\
\text { (Rp) }\end{array}$ \\
\hline 0 & - & - & - & $28.000 .000,-$ \\
\hline 2018 & $28.000 .000,-$ & $2.600 .000,-$ & $2.600 .000,-$ & $25.400 .000,-$ \\
\hline 2019 & $28.000 .000,-$ & $2.600 .000,-$ & $5.200 .000,-$ & $22.800 .000,-$ \\
\hline 2020 & $28.000 .000,-$ & $2.600 .000,-$ & $7.800 .000,-$ & $20.200 .000,-$ \\
\hline 2021 & $28.000 .000,-$ & $2.600 .000,-$ & $10.400 .000,-$ & $17.600 .000,-$ \\
\hline 2022 & $28.000 .000,-$ & $2.600 .000,-$ & $13.000 .000,-$ & $15.000 .000,-$ \\
\hline 2023 & $28.000 .000,-$ & $2.600 .000,-$ & $15.600 .000,-$ & $12.400 .000,-$ \\
\hline 2024 & $28.000 .000,-$ & $2.600 .000,-$ & $18.200 .000,-$ & $9.800 .000,-$ \\
\hline
\end{tabular}




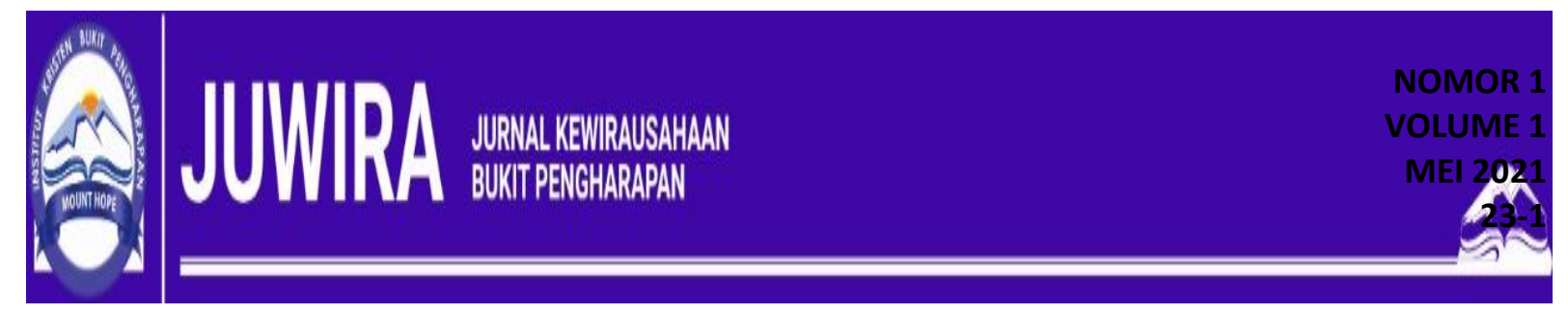

\begin{tabular}{|l|l|l|l|l|}
\hline 2025 & $28.000 .000,-$ & $2.600 .000,-$ & $20.800 .000,-$ & $7.200 .000,-$ \\
\hline 2026 & $28.000 .000,-$ & $2.600 .000,-$ & $23.400 .000,-$ & $4.600 .000,-$ \\
\hline 2027 & $28.000 .000,-$ & $2.600 .000,-$ & $26.000 .000,-$ & $2.000 .000,-$ \\
\hline
\end{tabular}

Table. 2 ini berisikan perhitungan penyusutan mesin foto copy dengan metode garis lurus dengan menggunakn rumus harga perolehan mesin foto copy Rp 28.000.000,- di kurang dengan nilai residu Rp 2.000.000,- di bagi umur ekonomis mesi foto copy 10 tahun mendapat nilai penyusutan pertahunnya adalah $\mathrm{Rp} 2.600 .000,-/$ tahun dan nilai penyusutan pertahunnya sama.

Tabel.3

Penyusutan Aktiva Tetap Mesin Laminating Dengan Metode Garis Lurus.

\begin{tabular}{|c|c|c|c|c|}
\hline Tahun & $\begin{array}{c}\text { Harga } \\
\text { Perolehan } \\
\text { (Rp) }\end{array}$ & $\begin{array}{c}\text { Depresiasi per } \\
\text { Tahun } \\
(\mathbf{R p})\end{array}$ & $\begin{array}{c}\text { Akum. Depresiasi } \\
\text { Akhir Tahun } \\
\text { (Rp) }\end{array}$ & $\begin{array}{c}\text { Nilai Buku Akhir } \\
\text { Tahun } \\
\text { (Rp) }\end{array}$ \\
\hline 0 & - & - & - & $1.600 .000,-$ \\
\hline 2018 & $1.600 .000,-$ & $280.000,-$ & $280.000,-$ & $1.320 .000,-$ \\
\hline 2019 & $1.600 .000,-$ & $280.000,-$ & $560.000,-$ & $1.040 .000,-$ \\
\hline 2020 & $1.600 .000,-$ & $280.000,-$ & $840.000,-$ & $760.000,-$ \\
\hline 2021 & $1.600 .000,-$ & $280.000,-$ & $1.120 .000,-$ & $480.000,-$ \\
\hline 2022 & $1.600 .000,-$ & $280.000,-$ & $1.400 .000,-$ & $200.000,-$ \\
\hline
\end{tabular}

Tabel. 3 ini berisikan perhitungan penyusutan mesin laminating dengan metode garis lurus dengan menggunakn rumus harga perolehan mesin laminating Rp 1.600.000,- di kurang dengan nilai residu Rp 200.000,- di bagi umur ekonomis mesin laminating 5 tahun mendapat nilai penyusutan pertahunnya adalah $\mathrm{Rp} 280.000,-/$ tahun dan nilai penyusutan pertahunnya sama.

Tabel.4

Penyusutan Aktiva Tetap Mesin Potong Kertas Dengan Metode Garis Lurus.

\begin{tabular}{|c|c|c|r|r|}
\hline Tahun & $\begin{array}{c}\text { Harga } \\
\text { Perolehan } \\
\text { (Rp) }\end{array}$ & $\begin{array}{c}\text { Depresiasi per } \\
\text { Tahun } \\
(\mathbf{R p})\end{array}$ & $\begin{array}{c}\text { Akum. Depresiasi } \\
\text { Akhir Tahun } \\
\text { (Rp) }\end{array}$ & $\begin{array}{c}\text { Nilai Buku } \\
\text { Akhir Tahun } \\
\text { (Rp) }\end{array}$ \\
\hline 0 & - & - & - & $2.500 .000,-$ \\
\hline 2018 & $2.500 .000,-$ & $420.000,-$ & $420.000,-$ & $2.080 .000,-$ \\
\hline 2019 & $2.500 .000,-$ & $420.000,-$ & $560.000,-$ & $1.660 .000,-$ \\
\hline 2020 & $2.500 .000,-$ & $420.000,-$ & $840.000,-$ & $1.240 .000,-$ \\
\hline 2021 & $2.500 .000,-$ & $420.000,-$ & $1.120 .000,-$ & $820.000,-$ \\
\hline 2022 & $2.500 .000,-$ & $420.000,-$ & $1.400 .000,-$ & $400.000,-$ \\
\hline
\end{tabular}

Tabel. 4 ini berisikan perhitungan penyusutan mesin potong kertas dengan metode garis lurus dengan menggunakn rumus harga perolehan mesin potong kertas $\mathrm{Rp} 2.500 .000$,- di kurang dengan nilai residu $\mathrm{Rp} 400.000$,- di bagi umur ekonomis mesin potong kertas 5 tahun mendapat nilai penyusutan pertahunnya adalah $\mathrm{Rp} 420.000$,-/tahun dan nilai penyusutan pertahunnya sama.

Tabel. 5

Penyusutan Aktiva Tetap Leptop Dengan Metode Garis Lurus 


\begin{tabular}{|c|c|c|c|c|}
\hline Tahun & $\begin{array}{c}\text { Harga } \\
\text { Perolehan } \\
(\mathbf{R p})\end{array}$ & $\begin{array}{c}\text { Depresiasi per } \\
\text { Tahun } \\
(\mathbf{R p})\end{array}$ & $\begin{array}{c}\text { Akum. depresiasi } \\
\text { Akhir Tahun } \\
(\mathbf{R p})\end{array}$ & $\begin{array}{c}\text { Nilai Buku } \\
\text { Akhir Tahun } \\
\text { (Rp) }\end{array}$ \\
\hline 0 & - & - & - & $3.800 .000,-$ \\
\hline 2018 & $3.800 .000,-$ & $660.000,--$ & $660.000,-$ & $3.140 .000,-$ \\
\hline 2019 & $3.800 .000,-$ & $660.000,-$ & $1.320 .000,-$ & $2.480 .000,-$ \\
\hline 2020 & $3.800 .000,-$ & $660.000,-$ & $1.980 .000,-$ & $1.820 .000,-$ \\
\hline 2021 & $3.800 .000,-$ & $660.000,-$ & $2.640 .000,-$ & $1.160 .000,-$ \\
\hline 2022 & $3.800 .000,-$ & $660.000,-$ & $3.300 .000,-$ & $500.000,-$ \\
\hline
\end{tabular}

Table. 5 ini berisikan perhitungan penyusutan laptop dengan metode garis lurus dengan menggunakn rumus harga perolehan laptop Rp 3.800.000,- di kurang dengan nilai residu Rp 500.000 ,- di bagi umur ekonomis laptop 5 tahun mendapat nilai penyusutan pertahunnya adalah $\mathrm{Rp} 660.000$,-/tahun dan nilai penyusutan pertahunnya sama.

Tabel. 6

Penyusutan Aktiva Tetap Printer Dengan Metode Garis Lurus.

\begin{tabular}{|c|c|c|c|r|}
\hline Tahun & $\begin{array}{c}\text { Harga } \\
\text { Perolehan } \\
\text { (Rp) }\end{array}$ & $\begin{array}{c}\text { Depresiasi per } \\
\text { Tahun } \\
\text { (Rp) }\end{array}$ & $\begin{array}{c}\text { Akum. Depresiasi } \\
\text { Akhir Tahun } \\
\text { (Rp) }\end{array}$ & $\begin{array}{c}\text { Nilai Buku } \\
\text { Akhir Tahun } \\
\text { (Rp) }\end{array}$ \\
\hline 0 & - & - & - & $700.000,-$ \\
\hline 2018 & $700.000,-$ & $140.000,-$ & $140.000,-$ & $560.000,-$ \\
\hline 2019 & $700.000,-$ & $140.000,-$ & $280.000,-$ & $420.000,-$ \\
\hline 2020 & $700.000,-$ & $140.000,-$ & $420.000,-$ & $280.000,-$ \\
\hline 2021 & $700.000,-$ & $140.000,-$ & $560.000,-$ & $140.000,-$ \\
\hline 2022 & $700.000,-$ & $140.000,-$ & $700.000,-$ & $0,-$ \\
\hline
\end{tabular}

Table. 6 ini berisikan perhitungan penyusutan printer dengan metode garis lurus dengan menggunakn rumus harga perolehan printer Rp 700.000,- di kurang dengan nilai residu Rp 0,di bagi umur ekonomis printer 5 tahun mendapat nilai penyusutan pertahunnya adalah Rp $140.000,-/ t a h u n$ dan nilai penyusutan pertahunnya sama.

\section{KESIMPULAN}

Penerapan perhitungan penyusutan aktiva tetap menggunkan metode garis lurus dari perhitungan penyusutan tersebut ditemukan penyusutan setiap aktiva tetap tersebut sama dari tahun ke tahun, adapun penyusutan tersebut, yaitu :

1. Penyusutan aktiva tetap mesin foto copy per tahun sebesar Rp 2.600.000,-

2. Penyusutan aktiva tetap mesin laminating per tahun sebesar Rp 280.000,-

3. Penyusutan aktiva tetap mesin potong kertas per tahun sebesar Rp 420.000,-

4. Penyusutan aktiva tetap leptop per tahun sebesar Rp 660.000,-

5. Penyusutan aktiva tetap printer per tahun sebesar Rp 140.000,-

Menggunakn metode garis lurus lebih mudah di gunakan dan di pahami dari segi perhitungannya dengan menggunakan rumus di atas. Dan pencatatan aktiva tetap bisa di lakukan dengan benar karena sudah menghitung penyusutan pertahunnya tetap sama.

\section{DAFTAR PUSTAKA}

Bramasto, A. R. I. (2007). Analisis Perputaran Aktiva Tetap Dan Perputaran Piutang Kaitannya Terhadap Return On Assets Pada Pt. Pos Indonesia (Persero) Bandung. Jurnal Ekonomi Unikom, 9(2), 215-230.

Budiman, E., Pangemanan, S., \& Tangkuman, S. (2014). Analisis Perlakuan Akuntansi Aktiva Tetap Pada Pt. Hasjrat Multifinance Manado 2012. Jurnal Riset Ekonomi, Manajemen, Bisnis Dan Akuntansi, 2(1), 411-420. 


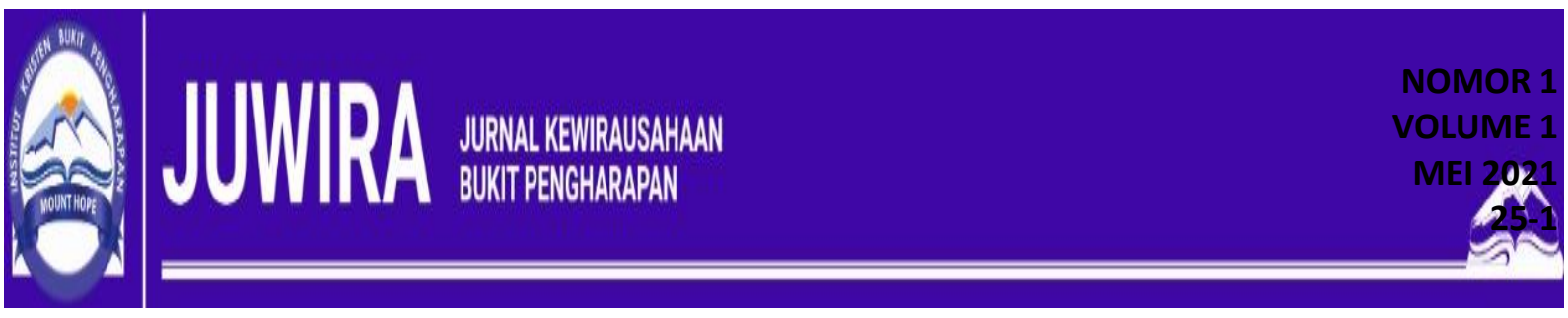

Https://Doi.Org/10.35794/Emba.V2i1.4005

Dokman Marulitua Situmorang, Erlina, B. S. (2018). Pengaruh Kompetensi Dan Independensi Auditor Terhadap Kualitas Audit Dengan Etika Auditor Sebagai Variabel Moderating Pada Kantor Akuntan Publik Di Kota Medan. Jurnal Ilmiah Akuntansi Dan Finansial Indonesia, 2(1), 29-40.

Dokman Marulitua Situmorang. (2019). The Effect Of Taxpayer Awarenes And Fiskus Service On Performance Of Tax Revenue With Taxpayer Compliance As Intervening Variables (Case Study Of Individual Taxpayers Registered At The Medan City Kpp Pratama). Management And Sustainable Development Journal, 1(1), $26-37$.

Koapaha, V. D., Sondakh, J. J., \& Pusung, R. J. (2014). Evaluasi Penerapan Perlakuan Akuntansi Aktiva Tetap Berdasarkan Psak No.16 Pada Rsup Prof.Dr.R.D. Kandou Manado. Jurnal Riset Ekonomi, Manajemen, Bisnis Dan Akuntansi, 2(3), 218-226. Https://Doi.Org/10.35794/Emba.V2i3.5435

Mairuhu, S., \& Tinangon, J. J. (2014). Analisis Penerapan Metode Penyusutan Aktiva Tetap Dan Implikasinya Terhadap Laba Perusahaan Pada Perum Bulog Divre Sulut Dan Gorontalo. Jurnal Emba, 2(4), 404-412.

Poere, D. B. De, \& Rosita, S. I. (2013). Tinjauan Perencanaan Pajak Sehubungan Pembelian Aktiva Tetap Berwujud Secara Tunai, Kredit Dan Leasing. Jurnal Ilmiah Akuntansi Kesatuan, 1(1), 51-57.

Pontoh, E. L., Morasa, J., \& Budiarso, N. S. (2016). Evaluasi Penerapan Perlakuan Akuntansi Terhadap Aktiva Tetap Berdasarkan Psak No.16 Tahun 2011 Pada Pt. Nichindo Manado Suisan. Jurnal Emba: Jurnal Riset Ekonomi, Manajemen, Bisnis Dan Akuntansi, 4(3), 68-77. Https://Doi.Org/10.35794/Emba.V4i3.13391

Rachmawati, S. (2018). Analisis Perputaran Piutang Dan Perputaran Aktiva Tetap Terhadap Profitabilitas Pada Pt. Gudang Garam.Tbk. Jesya (Jurnal Ekonomi \& Ekonomi Syariah), 1(2), 81-91. Https://Doi.Org/10.36778/Jesya.V1i2.20

Ratag, G. (2013). Perencanaan Pajak Melalui Metode Penyusutan Aktiva Tetap Untuk Menghitung Pph Badan Pada Pt. Bank Sulut. Jurnal Riset Ekonomi, Manajemen, Bisnis Dan Akuntansi, 1(3), 950-958.

Wijaya, S., \& Supandi, A. B. (2017). Analisis Revaluasi Aktiva Tetap Di Pt. Indonesia Power. Jurnal Pajak Indonesia (Indonesian Tax Journal), 1(1), 106-117. Http://Www.Jurnal.Stan.Ac.Id/Index.Php/Jpi/Article/View/171 